\title{
Citrus tristeza virus co-opts glyceraldehyde 3-phosphate dehydrogenase for its infectious cycle by interacting with the viral- encoded protein p23
}

\author{
Susana Ruiz-Ruiz ${ }^{1} \cdot$ Roberta Spanò $^{1,3} \cdot$ Luis Navarro $^{2} \cdot$ Pedro Moreno $^{2} \cdot$ Leandro Peña $^{1} \cdot$ Ricardo Flores $^{1}$ (D)
}

Received: 14 February 2018 / Accepted: 1 October 2018 / Published online: 3 November 2018

(c) Springer Nature B.V. 2018

\begin{abstract}
Key message Citrus tristeza virus encodes a unique protein, $\mathbf{p 2 3}$, with multiple functional roles that include co-option of the cytoplasmic glyceraldehyde 3-phosphate dehydrogenase to facilitate the viral infectious cycle.

Abstract The genome of citrus tristeza virus (CTV), genus Closterovirus family Closteroviridae, is a single-stranded (+) RNA potentially encoding at least 17 proteins. One (p23), an RNA-binding protein of 209 amino acids with a putative Zn-finger and some basic motifs, displays singular features: (i) it has no homologues in other closteroviruses, (ii) it accumulates mainly in the nucleolus and Cajal bodies, and in plasmodesmata, and (iii) it mediates asymmetric accumulation of CTV RNA strands, intracellular suppression of RNA silencing, induction of some CTV syndromes and enhancement of systemic infection when expressed as a transgene ectopically or in phloem-associated cells in several Citrus spp. Here, a yeast two-hybrid screening of an expression library of Nicotiana benthamiana (a symptomatic experimental host for CTV), identified a transducin/WD40 domain protein and the cytosolic glyceraldehyde 3-phosphate dehydrogenase (GAPDH) as potential host interactors with $\mathrm{p} 23$. Bimolecular fluorescence complementation corroborated the p23-GAPDH interaction in planta and showed that p23 interacts with itself in the nucleolus, Cajal bodies and plasmodesmata, and with GAPDH in the cytoplasm (forming aggregates) and in plasmodesmata. The latter interaction was preserved in a p23 deletion mutant affecting the C-terminal domain, but not in two others affecting the $\mathrm{Zn}$-finger and one internal basic motif. Virus-induced gene silencing of GAPDH mRNA resulted in a decrease of CTV titer as revealed by real-time RT-quantitative PCR and RNA gel-blot hybridization. Thus, like other viruses, CTV seems to co-opt GAPDH, via interaction with p23, to facilitate its infectious cycle.
\end{abstract}

Keywords Citrus tristeza virus $\cdot$ Closteroviruses $\cdot$ Plant RNA viruses $\cdot$ Virus-host interactions

\section{Introduction}

Citrus tristeza virus (CTV), genus Closterovirus within family Closteoviridae, is a phloem-restricted single-stranded (+) RNA virus that infects naturally some species of two genera

Ricardo Flores

rflores@ibmcp.upv.es

1 Instituto de Biología Molecular y Celular de Plantas, Consejo Superior de Investigaciones Científicas (CSIC)Universidad Politécnica de Valencia (UPV), Valencia, Spain

2 Instituto Valenciano de Investigaciones Agrarias (IVIA), Moncada, Valencia, Spain

3 Present Address: Dipartimento di Scienze del Suolo della Pianta e degli Alimenti, Università degli Studi di Bari "Aldo Moro", Bari, Italy of the family Rutaceae (Bar-Joseph et al. 1989; Moreno et al. 2008), and that may also infect systemically and incite symptoms in the previously presumed non-host Nicotiana benthamiana (Ambrós et al. 2011). The CTV genomic RNA (gRNA) contains 12 open reading frames (ORFs) potentially coding for at least 17 protein products flanked by $5^{\prime}$ and $3^{\prime}$ untranslated regions (UTR) (Karasev et al. 1995; Mawassi et al. 1996; Vives et al. 1999; Yang et al. 1999; AlbiachMartí et al. 2000; Harper 2013). ORFs 1a and 1b are directly translated from the gRNA and, together with the 5' and 3' UTRs, constitute the only regions required for RNA replication (Satyanarayana et al. 1999), while ORFs 2-11, spanning the 3'-terminal moiety of the gRNA, encode proteins p33, p6, p65, p61, p27, p25, p18, p13, p20 and p23, which are expressed via ten 3 '-coterminal subgenomic RNAs (Hilf et al. 1995). 
One of these proteins, p23, has no homologues in other closteroviruses, displays RNA-binding ability, and contains a putative zinc-finger domain and some basic motifs (López et al. 2000). CTV-p23 is a multifunctional protein (Flores et al. 2013), which besides suppressing RNA silencing in Nicotiana spp. (Lu et al. 2004; Ruiz-Ruiz et al. 2013), has been involved in mediating at least two important virushost interactions. First, when expressed as a transgeneectopically or in phloem-associated cells-it elicits CTVlike symptoms in several Citrus spp., but not in Nicotiana spp. (Fagoaga et al. 2005; Ghorbel et al. 2001; Soler et al. 2014); in agreement with this feature, the polymorphism of a specific p23 region allows discrimination between mild and severe CTV isolates (Sambade et al. 2003). And second, it regulates the asymmetrical accumulation of CTV $(+)$ and $(-)$ strands during RNA replication (Satyanarayana et al. 2002). Moreover, $p 23$ accumulates preferentially in the nucleolus and Cajal bodies, being the first closterovirus protein with such a subcellular localization, as well as in plasmodesmata (Ruiz-Ruiz et al. 2013).

Dissecting the interactions between virus- and hostencoded proteins has contributed significantly to our understanding of the dynamics of viral infection. Complexes between both kinds of proteins and viral genomes mediate replication, intercellular movement and systemic trafficking of viruses (Heinlein 2015). Replication of typical RNA viruses takes place in the cytoplasm in organelle-like membranous vesicles, called viral replication complexes (VRC) or "viral factories", formed by host components and viral-encoded proteins (den Boon and Ahlquist 2010). The movement proteins encoded by some plant RNA viruses may bind to the VRC and facilitate their association with plasmodesmata and the subsequent viral spread (Heinlein 2015). Most proteins encoded by viruses, including suppressors of RNA silencing, are multifunctional and can operate as pathogenicity determinants, triggering the host defensive responses and also usurping and redirecting host pathways for virus replication and spread (García and Pallás 2015). Considering the unique properties of $\mathrm{p} 23$, we have examined in yeast a library of $N$. benthamiana for proteins interacting with it. After confirming independently in planta the interaction with one of the two candidates retrieved, the cytosolic glyceraldehyde 3-phosphate dehydrogenase (GAPDH), we have mapped the p23 domains involved in such interaction, and investigated the role of GAPDH in CTV accumulation.

\section{Results}

\section{Yeast hybrid screening identifies two interactors of CTV-p23 in N. benthamiana}

To pinpoint host proteins that might interact with $\mathrm{p} 23$, we performed a yeast two-hybrid (Y2H) analysis with a library of $N$. benthamiana, a model plant in which at least one CTV isolate (T36) replicates and incites symptoms (Ambrós et al. 2011). The Y2H screening resulted in two partners: the cytosolic GAPDH, with a main role in glycolysis, and a transducin/WD40 domain protein, the interactions of which with p23 as a bait were further confirmed in 1-by-1 yeast assays.

The interacting pairs were tested in duplicate, with two independent clones from each co-transformation being picked for the growth assay. For each interaction four dilutions $\left(10^{-1}, 10^{-2}, 10^{-3}\right.$ and $\left.10^{-4}\right)$ of the diploid yeast cell culture, normalized at $5 \times 10^{4}$ cells and expressing both bait and prey constructs, were spotted on several selective media. The DO-2 selective medium lacking tryptophan and leucine was used as a growth control. The identification of $N$. benthamiana proteins interacting with p23 was based on the reporter gene HIS3 (growth assay without histidine). For this aim, the different dilutions were also spotted on the selective medium DO-3 without tryptophan, leucine and histidine (Fig. 1a). Four increasing concentrations of 3-aminotriazol (3-AT), an inhibitor of the product of gene HIS3, were added to the DO-3 plates to intensify stringency and reduce possible auto-activation by p23 (Fig. 1b). The interactions of p23 with GAPDH and a transducin/WD40 domain protein were still visible when the selection medium was supplemented with $10 \mathrm{mM}$ 3-AT. Because the transducin/WD40 construct isolated in the $\mathrm{Y} 2 \mathrm{H}$ screening contained a stop codon between the Gal4 activation domain (Gal4-AD) and the transducin WD40 fragment, we suspected that this stop codon was partially over-read thus producing enough functional fusion protein to allow growth on the selective medium. Therefore, a fragment without this stop codon was cloned in frame with the Gal4-AD and tested for its potential interaction with $\mathrm{p} 23$. The interaction resisted a selection pressure up to $100 \mathrm{mM} 3$-AT, while the initial prey clone with the stop codon did not grow under these conditions (Fig. 1b). This result was most likely due to the production of a higher amount of the correct fusion protein, indicating that the transducin/WD40 fragment indeed interacted with p23. No growth was observed in the negative controls.

Altogether the in vivo yeast assay results showed that p23 interacts with GAPDH and a transducin/WD40 domain protein, opening the possibility that these interactions could also occur in planta. 
(a)
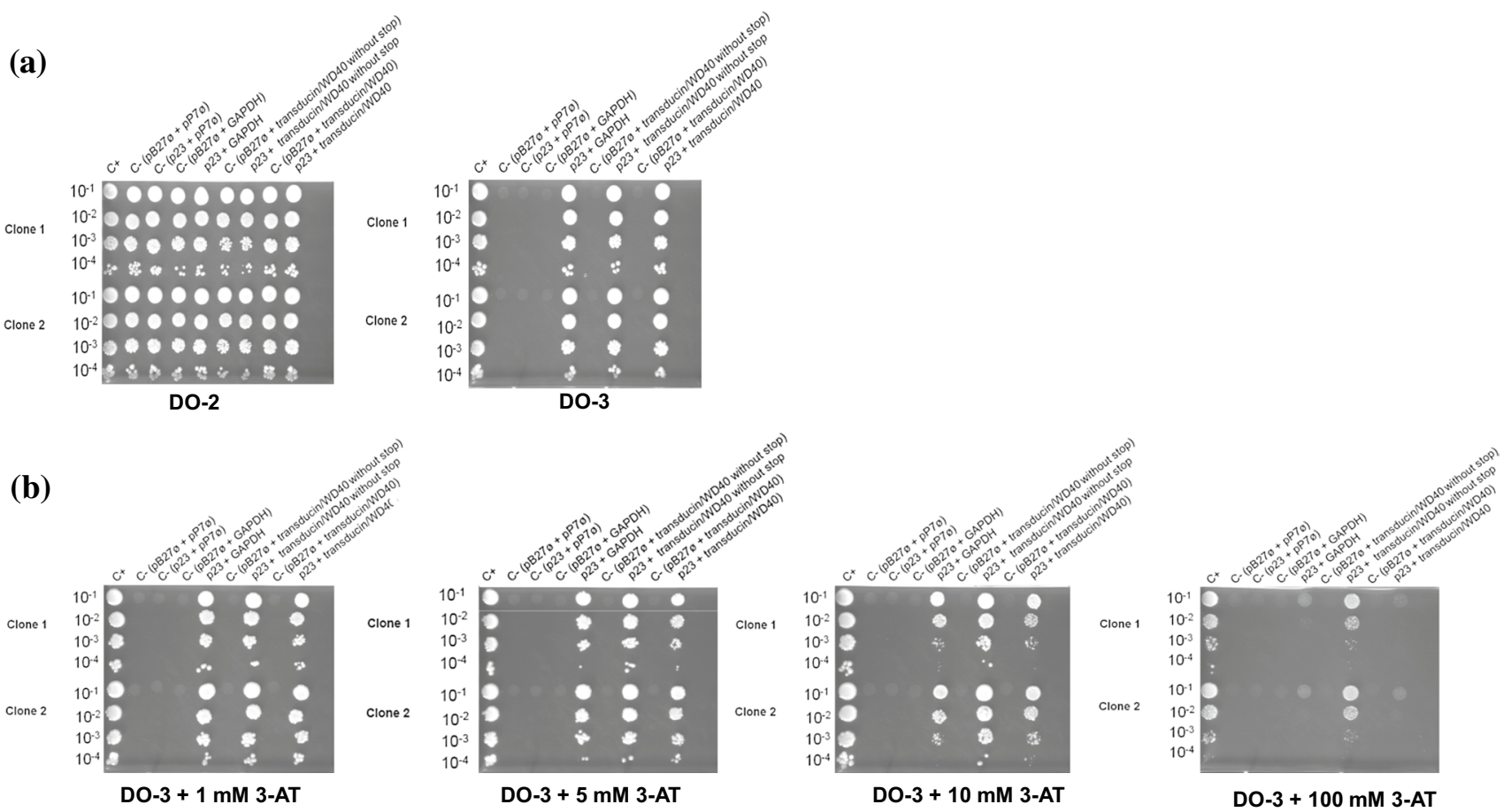

Fig. 1 Identification by yeast two hybrid screening of two proteins from a $N$. benthamiana expression library interacting with CTV-p23. Solid growth tests were performed on $-\mathrm{His}[ \pm 3 \mathrm{AT}]$ plates. For each interaction, two independent clones and several dilutions of the diploid yeast cells culture normalized at $5 \times 10^{4}$ cells and expressing both bait and prey constructs were spotted on several selective media. a The DO-2 selective medium lacking tryptophan and leucine was used

\section{Bimolecular fluorescence complementation (BiFC) reveals that CTV-p23 interacts in planta with itself and with GAPDH}

Because GAPDH has been specifically involved in the replication of some animal and plant single-stranded (+) RNA viruses (see below), we focused on this protein, but first we tested whether (and in such a case, where) p23 interacted with itself in $N$. benthamiana. For this purpose, we fused to gene $p 23$ the regions coding for the $\mathrm{N}$ - and C-terminal moieties of the yellow fluorescent protein (sYFP), resulting in sYFPN-p23 and sYFPC-p23 constructs, respectively. The epidermal cells of the agroinfiltrated leaves of $N$. benthamiana were examined by confocal laser-scanning microscopy at three days post-infiltration (dpi). Our results showed that p23 indeed interacts with itself, as revealed by the strong reconstitution of the sYFP fluorescence in leaves co-infiltrated with the binary plasmids expressing sYFPN-p23 and sYFPC-p23. In contrast, when the binary plasmid expressing sYFPN-p23 was co-infiltrated with that expressing sYFPC, or the binary plasmid expressing sYFPC-p23 was co-infiltrated with that expressing sYFPN, no fluorescence was detected (data not shown). The fluorescence generated as a growth control, and the different dilutions were also spotted on the selective medium DO-3 lacking tryptophan, leucine and histidine. b Four different concentrations of 3-AT, an inhibitor of the product from gene HIS3, were added to the DO-3 plates to increase stringency and reduce possible auto-activation by $\mathrm{p} 23$. Empty vectors are denoted by $\varnothing, \mathrm{C}+$ refers to interaction positive control from Hybrigenics and $\mathrm{C}-$ to negative controls as indicated in the figure by the interaction between sYFPN-p23 and sYFPC-p23 was observed in the nucleolus, Cajal bodies and cell membrane, being particularly visible in plasmodesmata (Fig. 2a).

Similarly, a strong fluorescence signal was detected in leaves co-infiltrated with the plasmids expressing sYFPNGAPDH and sYFPC-GAPDH. This fluorescence, observed in cytoplasmic granular aggregates of large size, most likely because this protein is homotetrameric (Jenkins and Tanner 2006) (Fig. 2b), indicated that GAPDH interacts with itself in N. benthamiana.

The interaction between p23 and GAPDH found in the Y2H screen, was confirmed in planta by co-infiltrating $N$. benthamiana leaves with plasmids expressing the fusion proteins sYFPC-p23 and sYFPN-GAPDH. Confocal laserscanning microscopy revealed fluorescent signals in the cytoplasm (forming aggregates) and in plasmodesmata, but neither in the nucleolus nor in other subnuclear compartments (Fig. 2c). No fluorescence signal was observed in control experiments in which the binary vectors expressing sYFPN-p23 or sYFPC-GAPDH were co-infiltrated with those expressing sYFPC or sYFPN, respectively (Fig. 2d).

In summary, these results showed that when interacting with themselves in $N$. benthamiana, p23 accumulates 
(a)

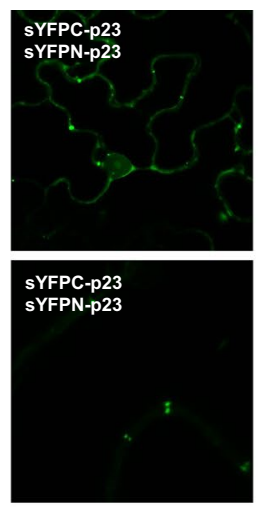

(b)

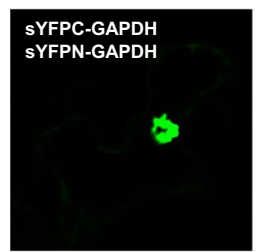

(c)
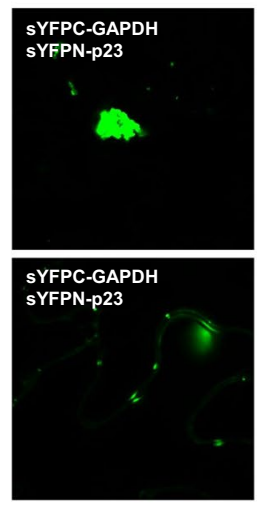

(d)
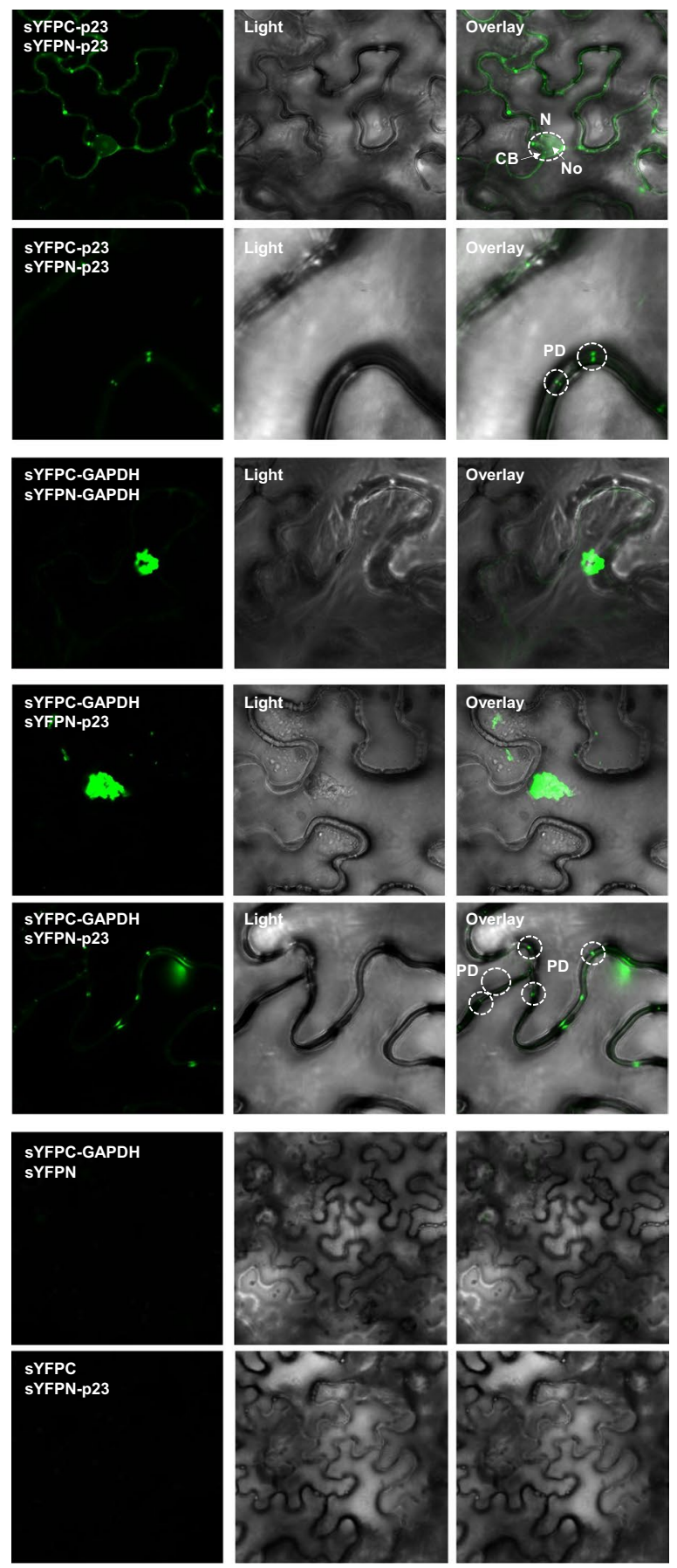

Fig. 2 Bimolecular fluorescence complementation assay in planta. Confocal laser-scanning microscopy of $N$. benthamiana leaves co-infiltrated with sYFPC-p23/sYFPN-p23 (a), sYFPC-GAPDH/ sYFPN-GAPDH (b), and sYFPC-GAPDH/sYFPN-p23 (c). No fluorescence signal was observed in all pairwise p23 and GAPDH combinations with the binary vector expresing sYFPN or sYFPC alone (d). Overlays confirms the self-interaction of p23 in the nucleolus (No) and Cajal bodies (CB), and in plasmodesmata (PD), the selfinteraction of GAPDH in the cytoplasm, and the interaction between p23 and GAPDH in the cytoplasm and plasmodesmata preferentially in the nucleolus, Cajal bodies and plasmodesmata, and GAPDH in the cytoplasm. In contrast, the complex p23-GAPDH was found in this latter compartment and also in plasmodesmata, but not in the two other major accumulation sites of p23 (nucleolus and Cajal bodies).

\section{Mapping the domains of CTV-p23 interacting with GAPDH}

To determine the specific domains of p23 interacting with GAPDH, we analyzed three deletion mutants of the former: (i) p23 $\Delta 50-86$, with a deletion including the putative $\mathrm{Zn}$ finger domain and an arginine- and lysine-rich motif, (ii) p23 $\Delta 100-209$, wherein the deletion included two basic amino acids motifs (positions 106-114 and 143-155), and (iii) p23 $\Delta 158-209$, in which the C-terminal 52 amino acids were deleted. In addition, we also examined two alanine substitution mutants: the first one affecting the four amino acids potentially coordinating the putative Zn-finger ion (C68/ $\mathrm{C} 71 / \mathrm{H} 75 / \mathrm{C} 85)$, and the second affecting a basic amino acid motif (R143/K145/R147/R150/R151/R155).

The five p23 mutants and the $N$. benthamiana GAPDH were tagged with the SYFPN and sYFPC halves, respectively, and the epidermal cells of the agroinfiltrated leaves were examined for fluorescence emission at $3 \mathrm{dpi}$. Interaction with GAPDH, as revealed by the reconstitution of YFP fluorescence forming aggregates in the cytoplasm, was observed with the p23 deletion mutant affecting the C-terminal domain (p23 158-209) and with the alanine substitution mutant affecting the four amino acids potentially coordinating the putative $\mathrm{Zn}$-finger ion $(\mathrm{C} 68 / \mathrm{C} 71 / \mathrm{H} 75 / \mathrm{C} 85)$, with the size of the aggregates being smaller than those generated by GAPDH and wild-type p23. With the other two deletion mutants (p23 $250-86$ and p23 $\Delta 100-209)$ and with the alanine substitution mutant affecting one internal basic motif (R143/K145/R147/R150/R151/R155), only a faint signal was observed in the cell membrane (Fig. 3). No, or negligible, fluorescence was detected in the negative controls. These results indicate that the p23 domain(s) responsible of the interaction with GAPDH is restricted to the N-terminal 157 amino acid fragment that includes three basic motifs (positions 51-86, 106-114, and 143-155). More specifically, the regions encompassing positions 51-86 and 143-155 are critical for the interaction of p23 with GAPDH, but neither the four amino acids potentially coordinating the putative $\mathrm{Zn}$ ion, nor the C-terminal 51 amino acids (positions 158-209).

\section{The cytoplasmic GAPDH has a significant role in CTV accumulation}

To examine whether the interaction between p23 and GAPDH could influence the accumulation of the fulllength CTV strands and their asymmetric balance, as 

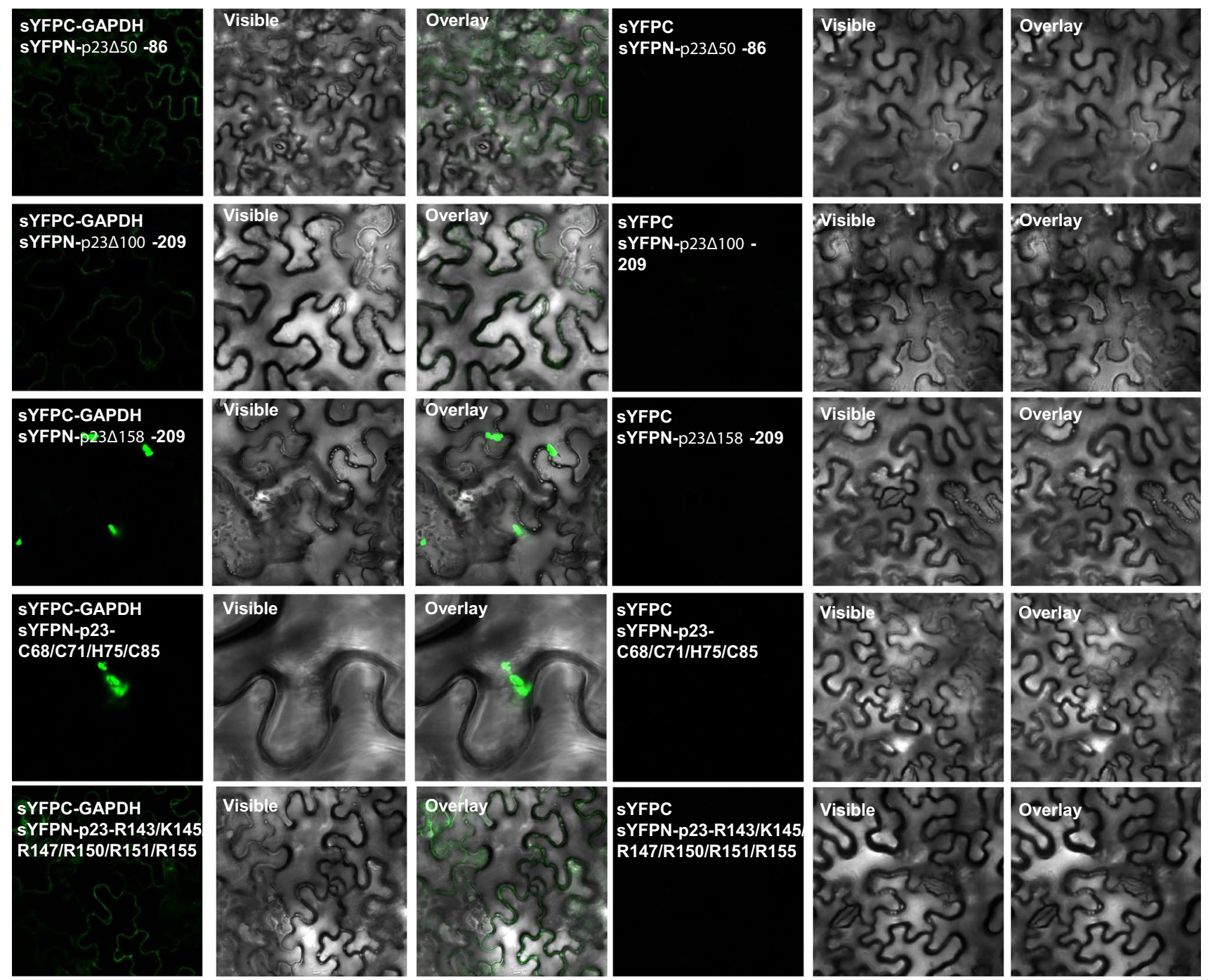

Fig. 3 Bimolecular fluorescence complementation assay in planta. Confocal laser-scanning microscopy of $N$. benthamiana leaves coinfiltrated with plasmids expressing GAPDH and three deletion and

observed with a tombusvirus (Wang and Nagy 2008), we cloned separately two regions ( 1 and 2 ) of the GAPDH gene from $N$. benthamiana into a vector based on tobacco rattle virus (TRV) (Dinesh-Kumar et al. 2003) to knock down GAPDH mRNA via virus-induced gene silencing (VIGS). The resulting plasmids, pTRVRNA2-GAPDH1 or pTRVRNA2-GAPDH2, were independently co-infiltrated with plasmid pTRVRNA1 in $N$. benthamiana leaves. Control experiments included plants co-infiltrated with the empty plasmids expressing TRVRNA2 and TRVRNA1. Gel-blot hybridization of total RNA preparations extracted at 15 dpi with a GAPDH-specific riboprobe, revealed a pronounced decrease of GAPDHmRNA in leaves of $N$. benthamiana co-infiltrated with pTRVRNA1 and pTRVRNA2-GAPDH1 or pTRVRNA2GAPDH2 with respect to the control plants (agroinfiltrated two alanine substitution mutants of p23. No fluorescence signal was observed in the negative controls

with pTRVRNA1 and pTRVRNA2) (Fig. 4a). Concomitantly, intense bands with the mobility expected for GAPDH-specific small interfering RNAs (siRNAs) of 21,22 , and 24 nucleotides (nt) were observed in leaves where the GAPDH-mRNA was undetectable, whereas the intensity of the GAPDH-siRNA bands became very much attenuated or negligible in leaves expressing high GAPDH-mRNA levels (Fig. 4a). No phenotypic differences were observed between those plants infiltrated with the empty viral vector and those with the vector containing regions of the GADPH gene. At this stage ( $15 \mathrm{dpi})$, new leaves of these plants were agroinfiltrated with a plasmid expressing a full-length cDNA of CTV-T36 (pCTV). RNA analysis at 21 days following this second agroinfiltration showed some recovery of GAPDH-mRNA levels in the plants initially silenced (Fig. 4b), an effect probably due 


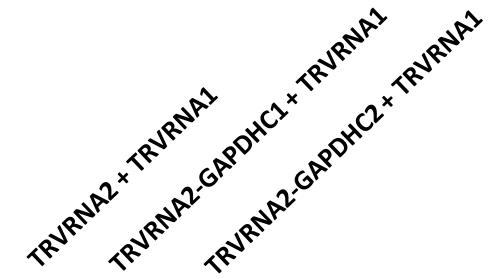

(a)

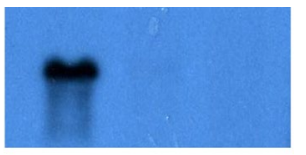

GAPDH mRNA

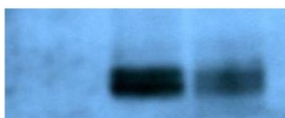

GAPDH SIRNA

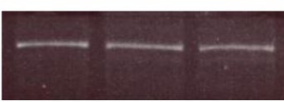

5S RNA

(b)

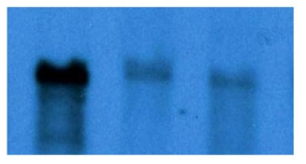

GAPDH mRNA

5S RNA

Fig. 4 VIGS of GAPDH expression in the absence and presence of CTV. a Accumulation of GAPDH mRNA and GAPDH-small interfering RNAs (siRNAs) at 15 dpi in upper leaves of $N$. benthamiana plants that were co-infiltrated with the empty plasmids TRVRNA2 and TRVRNA1, and with plasmids TRVRNA1 and TRVRNA2GAPDHC1 or TRVRNA2-GAPDHC2, in which two regions of the GAPDH-C cDNA from $N$. benthamiana were cloned separately. b At this stage ( $15 \mathrm{dpi})$, new leaves from these plants were agroinfiltrated with a plasmid for expressing a full-length cDNA of CTV-T36 and the accumulation of GAPDH mRNA and was examined 21 days later. Gel-blot hybridization was performed with a specific riboprobe following electrophoresis in denaturing agarose $(0.8 \%)$ and polyacrylamide $(17 \%)$ gels for detecting the GAPDH mRNA and siRNAs, respectively. The $5 \mathrm{~S}$ RNAs stained with ethidium bromide served as a loading control

to the expression of the three RNA silencing suppressors encoded by CTV (Lu et al. 2004).

Most importantly, real-time RT-quantitative PCR (RTqPCR) for specifically detecting the complete (+) and (-) CTV gRNA strands at 21 dpi with CTV, showed that VIGS of GAPDH mRNA with pTRVRNA1 and pTRVRNA2GAPDH 2 induced in three experiments a decrease of $29 \%$ $\left(2.9 \times 10^{5}\right.$ vs. $\left.4.1 \times 10^{5}\right), 32 \%\left(1.3 \times 10^{5}\right.$ vs. $\left.1.9 \times 10^{5}\right)$ and $63 \%\left(1.5 \times 10^{5}\right.$ vs. $\left.4.1 \times 10^{5}\right)$ in the accumulation of the gRNA (+) (with such decrease being statistically significant, P-value 0.02 , in an ANOVA analysis), and of $49 \%$ $\left(1.9 \times 10^{3}\right.$ vs. $\left.3.7 \times 10^{3}\right), 26 \%\left(1.7 \times 10^{3}\right.$ vs. $\left.2.3 \times 10^{3}\right)$ and $90 \%\left(3.7 \times 10^{3}\right.$ vs. $\left.3.6 \times 10^{4}\right)$ in that of the gRNA $(-)$ compared with the control plants agroinfiltrated with pTRVRNA1 and pTRVRNA2-empty (Table 1). These results support a significant role of GAPDH in CTV
Table 1 Effect of silencing the cytoplasmic GAPDH via VIGS on the accumulation of CTV gRNA strands

\begin{tabular}{|c|c|c|c|c|}
\hline Sample $^{\mathrm{a}}$ & $\mathrm{Ct} 1^{\mathrm{b}}$ & $\mathrm{Ct} 2$ & $\mathrm{Ct}$ mean & $\begin{array}{l}\text { Number of } \\
\text { molecules }^{c}\end{array}$ \\
\hline \multicolumn{5}{|l|}{ Experiment 1} \\
\hline $\begin{array}{l}\text { pCTV } \\
\text { Primer 198R for CTV gRNA } \\
(+)\end{array}$ & 17 & 17.07 & 17.03 & $2.3 \times 10^{6}$ \\
\hline $\begin{array}{l}\text { pTRVRNA2- } \\
\text { GAPDH2 + pCTV }\end{array}$ & 20.49 & 20.44 & 20.46 & $2.9 \times 10^{5}$ \\
\hline $\begin{array}{l}\text { Primer 198R for CTV gRNA } \\
(+)\end{array}$ & & & & \\
\hline $\begin{array}{l}\text { pTRVRNA2-empty + pCTV } \\
\text { Primer 198R for CTV gRNA } \\
(+)\end{array}$ & 19.87 & 19.90 & 19.89 & $4.1 \times 10^{5}$ \\
\hline $\begin{array}{l}\text { pCTV } \\
\text { Primer 197R for CTV gRNA } \\
\quad(-)\end{array}$ & 22.02 & 21.93 & 21.97 & $1.2 \times 10^{5}$ \\
\hline $\begin{array}{l}\text { pTRVRNA2- } \\
\text { GAPDH2 + pCTV }\end{array}$ & 28.94 & 28.79 & 28.87 & $1.9 \times 10^{3}$ \\
\hline $\begin{array}{l}\text { Primer 197R for CTV gRNA } \\
(-)\end{array}$ & & & & \\
\hline $\begin{array}{l}\text { pTRVRNA2-empty + pCTV } \\
\text { Primer 197R for CTV gRNA } \\
\quad(-)\end{array}$ & 27.77 & 27.73 & 27.75 & $3.7 \times 10^{3}$ \\
\hline Experiment 2 & & & & \\
\hline $\begin{array}{l}\text { pCTV } \\
\text { Primer 198R for CTV gRNA } \\
\quad(+)\end{array}$ & 16.02 & 15.98 & 16.00 & $4.2 \times 10^{6}$ \\
\hline $\begin{array}{l}\text { pTRVRNA2- } \\
\text { GAPDH2 + pCTV }\end{array}$ & 21.73 & 21.69 & 21.71 & $1.3 \times 10^{5}$ \\
\hline $\begin{array}{l}\text { Primer 198R for CTV gRNA } \\
\quad(+)\end{array}$ & & & & \\
\hline $\begin{array}{l}\text { pTRVRNA2-empty }+ \text { pCTV } \\
\text { Primer 198R for CTV gRNA } \\
\quad(+)\end{array}$ & 21.16 & 20.93 & 21.04 & $1.9 \times 10^{5}$ \\
\hline $\begin{array}{l}\text { pCTV } \\
\text { Primer 197R for CTV gRNA } \\
\quad(-)\end{array}$ & 19.57 & 19.61 & $19, .59$ & $5.0 \times 10^{5}$ \\
\hline $\begin{array}{l}\text { pTRVRNA2- } \\
\text { GAPDH2 + pCTV }\end{array}$ & 28.90 & 28.85 & 28.88 & $1.7 \times 10^{3}$ \\
\hline $\begin{array}{l}\text { Primer 197R for CTV gRNA } \\
(-)\end{array}$ & & & & \\
\hline $\begin{array}{l}\text { pTRVRNA2-empty }+ \text { pCTV } \\
\text { Primer 197R for CTV gRNA } \\
\quad(-)\end{array}$ & 28.44 & 28.33 & 28.35 & $2.3 \times 10^{3}$ \\
\hline Experiment 3 & & & & \\
\hline $\begin{array}{l}\text { pCTV } \\
\text { Primer 198R for CTV gRNA } \\
(+)\end{array}$ & 14.93 & 14.97 & 14.95 & $7.9 \times 10^{6}$ \\
\hline $\begin{array}{l}\text { pTRVRNA2- } \\
\text { GAPDH2 + pCTV }\end{array}$ & 21.59 & 21.52 & 21.56 & $1.5 \times 10^{5}$ \\
\hline $\begin{array}{l}\text { Primer 198R for CTV gRNA } \\
\qquad(+)\end{array}$ & & & & \\
\hline $\begin{array}{l}\text { pTRVRNA2-empty }+ \text { pCTV } \\
\text { Primer 198R for CTV gRNA } \\
\quad(+)\end{array}$ & 19.25 & 19.33 & 19.29 & $4.1 \times 10^{5}$ \\
\hline
\end{tabular}


Table 1 (continued)

\begin{tabular}{lcccc}
\hline Sample $^{\mathrm{a}}$ & $\mathrm{Ct}^{\mathrm{b}}$ & $\mathrm{Ct} 2$ & Ct mean & $\begin{array}{l}\text { Number of } \\
\text { molecules }^{\mathrm{c}}\end{array}$ \\
\hline $\begin{array}{l}\text { pCTV } \\
\text { Primer 197R for CTV gRNA } \\
(-)\end{array}$ & 19.10 & 19.20 & 19.15 & $6.4 \times 10^{5}$ \\
pTRVRNA2- & & & & \\
$\quad$ GAPDH2+pCTV & 27.70 & 27.80 & 27.75 & $3.7 \times 10^{3}$ \\
$\begin{array}{l}\text { Primer 197R for CTV gRNA } \\
(-)\end{array}$ & & & & \\
$\begin{array}{l}\text { pTRVRNA2-empty + pCTV } \\
\text { Primer 197R for CTV gRNA } \\
(-)\end{array}$ & 23.93 & 23.95 & 23.94 & $3.6 \times 10^{4}$ \\
\hline
\end{tabular}

${ }^{\text {a}}$ Plants were co-infiltrated with pTRVRNA1 and pTRVRNA2GAPDH2 or pTRVRNA2-empty as indicated, and 15 days later they were agroinfiltrated with pCTV. Nucleic acids were extracted at 21 dpi with pCTV and subjected to RT-qPCR for quantifying the CTV gRNA (+) and gRNA (-) using for reverse transcription primers PM198R or PM197F, respectively, and both primers for qPCR amplification

${ }^{\mathrm{b}}$ Threshold cycle $(\mathrm{Ct})$

${ }^{c}$ Estimated as reported previously (Ruiz-Ruiz et al. 2007). The higher accumulation of CTV gRNA (+) and gRNA (-), and the lower ratio gRNA (+) to gRNA (-) in the absence of TRV could result from some sort of antagonism of the latter on the fomer

accumulation, although the ratio of (+) to (-) strands was essentially unaffected.

\section{Discussion}

CTV, like any other virus, must recruit host proteins for essentially every step of its infectious cycle. In view of its high protein-coding capacity, CTV-host interactions must be multiple and complex. To get a deeper insight into such interactions, we focused on $\mathrm{p} 23$ given the singular features of this protein with roles on the accumulation of CTV RNA strands, RNA silencing suppression, pathogenesis and virus movement (Flores et al. 2013). We first screened a library of $N$. benthamiana, expressed in yeast, to search for proteins interacting with $\mathrm{p} 23$. We deliberately chose such a library from $N$. benthamiana, and not others from Arabidopsis thaliana, because the former is an experimental host for at least one CTV isolate (T36) (Ambrós et al. 2011), thus increasing the chances of detecting interactions physiologically meaningful. The analysis retrieved two major partners: the cytosolic GAPDH and a transducin/ WD40 domain protein. The first one, a promising candidate because it modulates the infectious cycle of different viruses (see below), was confirmed to interact with $\mathrm{p} 23$ in planta by BiFC, using again $N$. benthamiana. Incidentally, BiFC also showed that GAPDH interacts with itself, in agreement with its homotetrameric nature (Jenkins and
Tanner 2006), as also does p23, a novel property of this protein that may have functional implications. Other CTV self-interacting proteins include p20 and p33 (Gowda et al. 2000; Kang et al. 2017). Analysis of three deletion and two substitution mutants mapped the p23 domain(s) interacting with GAPDH to the N-terminal moiety, with a net positive charge, which has also been involved in other functions of p23 (Flores et al. 2013).

As expected, the self-interaction of $\mathrm{p} 23$ revealed by BiFC was observed in the same major accumulation sites determined previously (the nucleolus, Cajal bodies and plasmodesmata) by transiently expressing in $N$. benthamiana a fusion construct of $p 23$ and the green fluorescent protein gene ( $g f p)$ placed between the $35 \mathrm{~S}$ promoter of the cauliflower mosaic virus and the nopaline synthase terminator (NOS-t) (Ruiz-Ruiz et al. 2013). However, when interacting with GAPDH, p23 was only detected in plasmodesmata as well as in the cytoplasm (the major accumulation site of GAPDH). These results are consistent with GAPDH assisting p23 in viral cell-to-cell movement through plasmodesmata. Besides its localization in these channels traversing cell walls, involvement of p23 in CTV movement is supported by the phloem escape of the virus observed in p23-expressing transgenic sweet orange (Citrus sinensis L. Osb.) and sour orange ( $C$. aurantium $\mathrm{L}$.) and by the enhancement of systemic infection (and virus accumulation) in the less-susceptible sour orange host (Fagoaga et al. 2011). Moreover, another GAPDH isoform (GAPDH-A, a component of the Calvin-Benson cycle in chloroplasts), recruits the movement protein of red clover necrotic mosaic virus, a bipartite single-stranded (+) RNA virus, to cortical virus replication complexes to facilitate viral cell-to-cell movement (Kaido et al. 2014).

Among the diversity of host proteins co-opted by several viruses, GAPDH holds a prominent position. This multifunctional protein has been implicated in a variety of cellular processes other than its key role in glycolysis, including replication/accumulation and gene expression of certain singlestranded (+) RNA viruses (White and Garcin 2016), as well as in their movement (see above). The GAPDH amino acid sequence is highly conserved across species, as also is its RNA-binding ability (White and Garcin 2016), which most likely mediates many of its extra-glycolytic functions. Replication of single-stranded (+) RNA viruses starts producing (-) RNA strands, which are the template for synthesis of $(+)$ RNA progeny strands in an asymmetric process resulting in a 10- to 1000-fold excess of the latter. This ratio is approximately 10:1 for flaviviruses (Chambers et al. 1990), 20:1 for tomato bushy stunt virus (TBSV) (Pogany and Nagy 2008), 50-100:1 for coronaviruses (Lai and Cavanagh 1997), 100:1 for brome mosaic virus (French and Ahlquist 1987; Marsh et al. 1991), and 1000:1 for alfalfa mosaic virus (Nassuth and Bol 1983). The estimates for CTV are 50:1 by gel-blot 
hybridization (Satyanarayana et al. 2002) and 10:1-100:1 by RT-qPCR (this work, Table 1).

The majority of RNA viruses with which GAPDH interacts have single-stranded (+) genomes, with this protein being coopted to either stabilize the viral RNA and/or alter the progeny ratio of (+) to (-) strands. More specifically, GAPDH stabilizes the genomic RNA of hepatitis $\mathrm{C}$ virus by binding to its 3'-UTR (Petrik et al. 1999), as also does with the genomic RNA of hepatitis A virus by competing with other cellular proteins for RNA binding (Dollenmaier and Weitz 2003; Yi et al. 2000); however, GAPDH binds preferentially the (-) RNA strand of Japanese encephalitis virus, remaining unclear the biological consequences of this interaction (Yang et al. 2009). In the context of plant RNA viruses, knockdown of GAPDH in $N$. benthamiana showed that GAPDH binding to the 3 '-UTR of the genomic RNAs of bamboo mosaic virus and its satellite virus, prevents transcription of the (-) RNA and halts the replication process reducing the ratio of $(-)$ to $(+)$ strands (Prasanth et al. 2011). On the other hand, by binding selectively to an AU pentameric sequence close to the $3^{\prime}$ terminus of the (-) RNA strand of TBSV, GAPDH retains this strand in the replication complex for its reiterative copying to produce an excess of (+) RNA strands. In fact, depletion of GAPDH preferentially inhibits the accumulation of $(+)$ RNA, resulting in a 1:1 ratio of (+) to (-) RNA products in yeast and in $N$. benthamiana (Wang and Nagy 2008; Huang and Nagy 2011).

In line with these previous reports, our data also uphold a role for GAPDH in replication/accumulation of CTV, because VIGS of GAPDH mRNA caused a decrease in the levels of (+) and (-) CTV strands. However, since the decrease was similar for both strands (about 29-32\% and $26-49 \%$, respectively), their ratio remained essentially unchanged. Considering the rather complex experimental design, involving VIGS of GAPDH mRNA and 15 days later infection by CTV, with its strand accumulation being examined after other additional 21 days, it is likely that adjusting these time lapses could result in even more pronounced effects. Moreover, changes in the sour orange transcriptome 4 months after infection with the asymptomatic CTV isolate T385 include the overexpression of GAPDH (Comellas 2009). In summary, results from VIGS of GAPDH mRNA in an experimental system ( $N$. benthamiana) together with the overaccumulation of this RNA during infection of a natural host (sour orange), support the involvement of GAPDH in facilitating the CTV infectious cycle.

\section{Materials and methods}

\section{Yeast two hybrid and 1-by-1 assays}

To identify host proteins interacting with CTV-p23, the coding sequence of this protein from isolate T36 was cloned in frame with the LexA DNA binding domain (DBD) into plasmid pB27, derived from the original pBTM116 (Vojtek and Hollenberg 1995). The DBD construct was checked by sequencing the entire insert. Clones of the $N$. benthamiana library (Hybrygenics) were arranged in frame with the Gal4 activation domain (AD) into plasmids $\mathrm{pP} 6$ or $\mathrm{pP} 7$ that derive from the original pGAD GH (Bartel et al. 1993).

Identification of $N$. benthamiana proteins interacting with p23 as bait was based on the reporter gene HIS3 (growth assay without histidine). The interaction pairs were tested using a mating protocol with $\mathrm{L} 40 \Delta \mathrm{Gal} 4$ (MATa) and Y187 (MAT $\alpha$ ) yeast strains, and in duplicate since two independent clones from each co-transformation were picked for the growth assay. For each interaction, several dilutions $\left(10^{-1}\right.$, $10^{-2}, 10^{-3}$ and $10^{-4}$ ) of the diploid yeast cells culture, normalized at $5 \times 10^{4}$ cells and expressing both bait and prey constructs, were spotted on several selective media. The DO-2 selective medium lacking tryptophan and leucine was used as a growth control and to verify the co-transformation of the bait and prey plasmids. The different dilutions were also spotted on a selective medium without tryptophan, leucine and histidine (DO-3). Four different concentrations $(1,5,10$ and $100 \mathrm{mM})$ of 3-aminotriazol (AT), an inhibitor of gene HIS3 product, were added to the DO-3 plates to increase stringency and reduce possible autoactivation by $\mathrm{p} 23$. The following interaction pairs, empty $\mathrm{pB} 27$-empty pP7, empty pB27-pP7-GAPDH, empty pB27-pP7-transducin/WD40 without stop codon and empty pB27-pP7transducin/WD40, were included as negative controls and tested using a mating protocol with L40 $\Delta$ Gal4 (MATa) and Y187 (MAT $\alpha$ ) yeast strains (Fromont-Racine et al. 1997).

\section{Analysis by bimolecular fluorescence complementation (BiFC)}

Vectors for BiFC assays were generated by PCR amplifying the sequences coding for $\mathrm{p} 23$, three deletion mutants (p23 $\Delta 50-86, \mathrm{p} 23 \Delta 100-209$ and p23 $2158-209)$ and two alanine substitution mutants (R143/K145/R147/R150/ $\mathrm{R} 151 / \mathrm{R} 155$ and C68/C71/H75/C85), with appropriate primers containing BamHI/SacI restriction sites, from a complete CTV-cDNA clone or from p23-cDNA clones with the corresponding deletions or substitutions (Ruiz-Ruiz et al. 2013). Regions or motifs delimited by positions $50-86$ and 143-155, both rich in basic amino acids and the first also encompassing a $\mathrm{Zn}$-finger, are involved in a bipartite nucleolar localization signal of p23 (Ruiz-Ruiz et al. 2013). The complete coding sequence for GAPDH was amplified from a $N$. benthamiana nucleic acid preparation by RT-PCR with primers containing BamHI/SacI restriction sites, derived from sequence alignments of GAPDH-cDNAs from other Nicotiana spp. All the PCR products were restricted with $\mathrm{BamHI} / \mathrm{SacI}$ and cloned into the polylinker (digested with 
the same enzymes) of pROK2-based binary vectors (kindly provided by Dr. Tomás Cantó) harboring the $\mathrm{N}$ - or the C-moieties of the sYFP (amino acids 1-154 and 155-238, respectively). All the resulting pROK2-sYFP-PCR product fusion constructs were electroporated into cells of Agrobacterium tumefaciens strain C58.

The transformed bacterial cultures were resuspended in infiltration buffer (10 mM MES, pH 5.6, $10 \mathrm{mM} \mathrm{MgCl}_{2}$, $150 \mu \mathrm{M}$ acetosyringone) to a final optical density of 0.5 at $600 \mathrm{~nm}$, incubated at room temperature for $3 \mathrm{~h}$ and then infiltrated in leaves of $N$. benthamiana for transient expression. In co-infiltration assays, equal volumes of the bacterial suspensions carrying GAPDH and p23 or its mutants were mixed previously. Plants were kept in growth chambers ( $16 \mathrm{~h}$ of light at $25^{\circ} \mathrm{C}$ and $8 \mathrm{~h}$ of darkness at $22^{\circ} \mathrm{C}$ ), and the agroinfiltrated leaves were examined 2 or 3 days later with a confocal laser-scanning microscope (Leica TCS-SL, Heidelberg, Germany) equipped with appropriate emission sources and filters. Ten independent co-infiltration experiments were performed, with the fluorescent signal being observed in most of the cells in at least 30 leaf sections. In order to see well-defined signals, particularly in plasmodesmata, the power of the laser had to be increased and sometimes not all organelles could be focused in the same plane.

\section{Virus-induced gene silencing (VIGS) and RNA gel-blot hybridization}

VIGS vectors were generated by PCR, amplifying two fragments of the GAPDH cDNA from $N$. benthamiana (GAPDH1 and GAPDH2 covering positions 260-700 and 562-1015, respectively) and then cloned into a TRV RNA 2 -based vector (Dinesh-Kumar et al. 2003). The resulting plasmids, pTRVRNA2-GAPDH1 and pTRVRNA2GAPDH2, were electroporated into A. tumefaciens cells and each of them was co-infiltrated separately in $N$. benthamiana plants with an A. tumefaciens culture harboring a TRV RNA 1 plasmid (final optical density of 0.1 at $600 \mathrm{~nm}$ ). At $15 \mathrm{dpi}$, total nucleic acid preparations from $N$. benthamiana were fractionated by electrophoresis in denaturing $0.9 \%$ agarose/ formaldehyde gels (for GAPDH mRNA separation), or in $17 \%$ polyacrylamide/8 $\mathrm{M}$ urea gels (for siRNAs separation) and transferred into Hybond-N + nylon membranes (Roche Diagnostics). At this stage (15 dpi), new leaves of these plants were agroinfiltrated with a plasmid carrying a full-length cDNA of CTV (isolate T36) and 21 days after this second agroinfiltration, total nucleic acid preparations were again fractionated and transferred as indicated above. A digoxigenin-labeled riboprobe specific for detecting GAPDH mRNA and siRNAs was generated by in vitro transcription, using the DIG RNA labeling mix (Roche Diagnostics), from the first $260 \mathrm{nt}$ of the the corresponding ORF. After overnight hybridization at $68{ }^{\circ} \mathrm{C}$ (for GAPDH
mRNA) or at $42{ }^{\circ} \mathrm{C}$ (for siRNAs) in ULTRAhyb hybridization buffer (Ambion), the membranes were washed twice with $2 \times \mathrm{SSC}(1 \times \mathrm{SSC}$ is $0.15 \mathrm{M} \mathrm{NaCl}, 0.015 \mathrm{M}$ sodium citrate) plus $0.1 \%$ sodium dodecyl sulfate (SDS) at room temperature for $10 \mathrm{~min}$, twice with $0.1 \times$ SSC plus $0.1 \%$ SDS at $42{ }^{\circ} \mathrm{C}$ for $15 \mathrm{~min}$, and revealed by incubation with the chemiluminescent substrate CSPD (Roche Diagnostics) and exposure to X-ray film. Equal loading was assessed by UV spectrophotometry and by the intensity of 5S RNA bands after electrophoresis in 5\% polyacrylamide/8 $\mathrm{M}$ urea gels.

\section{RT-qPCR}

Total nucleic acid preparations from $N$. benthamiana leaves (500 mg) co-infiltrated with pTRVRNA1 and pTRVRNA2GAPDH2, and 15 days later agroinfiltrated with pCTV, were extracted twice with phenol/chloroform/isoamylic alcohol at 21 days after the second agroinoculation. The RNAs recovered by ethanol precipitation were resuspended in $25 \mu \mathrm{l}$ of RNase-free water, treated with RNase-free DNase as recommended by the supplier (Ambion), adjusted to approximately $10 \mathrm{ng} / \mu \mathrm{l}$ and then measured in duplicate with the Quant-iTTM RiboGreen RNA Assay Kit (Invitrogen). RNAs from control plants (co-infiltrated with the empty plasmids expressing TRVRNA 2 and TRVRNA 1 and then agroinfiltrated with a plasmid for expressing the full-length RNA of CTV-T36 were included). Aliquots were stored at $-80{ }^{\circ} \mathrm{C}$. RT-qPCR for specifically detecting the CTV genomic RNA and its full complementary strand was performed using primers PM198R or PM197F (derived from ORFs 1b and 2) for reverse transcription, and both primers for quantitative PCR amplification as reported previously (Ruiz-Ruiz et al. 2007), in a LightCycler® platform (Roche Diagnostics) with $20 \mu \mathrm{l}$ glass capillaries.

\section{Statistical analysis}

The decrease in the accumulation level of the full-length $(+)$ and (-) CTV gRNA strands at 21 dpi with CTV in plants of $N$. benthamiana in which GAPDH mRNA was silenced by VIGS with respect to non-silenced plants, was assessed by one-way ANOVA analysis (Bewick et al. 2004).

Acknowledgements This research was supported by a Grant (Prometeo/2008/121) from the Generalitat Valenciana, Spain, and by a Grant (AGL2009-08052) from the Ministerio de Ciencia e Innovación-Fondo Europeo de Desarrollo Regional. S. Ruiz-Ruiz has been additionally supported by a postdoctoral contract from the Generalitat Valenciana (APOSTD/2012/020, Program VALi+d). We thank Dr. Pedro Serra for his help with the statistical analysis.

Author contributions SRR and RS performed the experiments and wrote the associated methods; all authors contributed with specific ideas and analyzed the data; RF conceived the project, supervised the experiments and wrote the article with the contributions of all authors. 


\section{References}

Albiach-Martí MR, Mawassi M, Gowda S, Satanarayana T, Hilf ME, Shanker S, Almira EC, Vives MC, López C, Guerri J, Flores R, Moren P, Garnsey SM, Dawson WO (2000) Sequences of citrus tristeza virus separated in time and space are essentially identical. J Virol 74:6856-6865

Ambrós S, El-Mohtar C, Ruiz-Ruiz S, Peña L, Guerri J, Dawson WO, Moren P (2011) Agroinoculation of Citrus tristeza virus causes systemic infection and symptoms in the presumed nonhost Nicotiana benthamiana. Mol Plant Microb Interact 24:1119-1131

Bar-Joseph M, Marcus R, Lee RF (1989) The continuous challenge of citrus tristeza virus control. Annu Rev Phytopathol 27:291-316

Bartel PL, Chien C-T, Sternglanz R, Fields S (1993) Using the twohybrid system to detect protein-protein interactions. In: Hartley DA (ed) Cellular interactions in development: a practical approach. Oxford University Press, Oxford, pp 153-179

Bewick V, Cheek L, Ball J (2004) Statistics review 9: one-way analysis of variance. Crit Care 8:130-136

Chambers TJ, Hahn CS, Galler R, Rice CM (1990) Flavivirus genome organization, expression, and replication. Annu Rev Microbiol 44:649-688

Comellas M (2009) Estudio de la interacción entre naranjo amargo y el virus de la tristeza de los cítricos. Tesis doctoral. Universidad Politécnica de Valencia, Valencia

den Boon JA, Ahlquist P (2010) Organelle-like membrane compartmentalization of positive-strand RNA virus replication factories. Annu Rev Microbiol 64:241-256

Dinesh-Kumar SP, Anandalakshmi R, Marathe R, Schiff M, Liu $\mathrm{Y}$ (2003) Virus-induced gene silencing. Methods Mol Biol 236:287-294

Dollenmaier G, Weitz M (2003) Interaction of glyceraldehyde-3-phosphate dehydrogenase with secondary and tertiary RNA structural elements of the hepatitis A virus 3 ' translated and non-translated regions. J Gen Virol 84:403-414

Fagoaga C, López C, Moreno P, Navarro L, Flores R, Peña L (2005) Viral-like symptoms induced by the ectopic expression of the $\mathrm{p} 23$ of Citrus tristeza virus are citrus specific and do not correlate with the pathogenicity of the virus strain. Mol Plant-Microb Interact 18:435-445

Fagoaga C, Pensabene G, Moreno P, Navarro L, Flores R, Peña L (2011) Ectopic expression of the p23 silencing suppressor of Citrus tristeza virus differentially modifies viral accumulation and tropism in two transgenic woody hosts. Mol Plant Pathol 12:898-910

Flores R, Ruiz-Ruiz S, Soler N, Sánchez-Navarro J, Fagoaga C, López C, Navarro L, Moreno P, Peña L (2013) Citrus tristeza virus p23: a unique protein mediating key virus-host interactions. Front Microbiol 4:98

French R, Ahlquist P (1987) Intercistronic as well as terminal sequences are required for efficient amplification of brome mosaic virus RNA3. J Virol 61:1457-1465

Fromont-Racine M, Rain JC, Legrain P (1997) Toward a functional analysis of the yeast genome through exhaustive two-hybrid screens. Nat Genet 16:277-282

García JA, Pallás V (2015) Viral factors involved in plant pathogenesis. Curr Opin Virol 11:21-30

Ghorbel R, López C, Fagoaga C, Moreno P, Navarro L, Flores R, Peña L (2001) Transgenic citrus plants expressing the Citrus tristeza virus p23 protein exhibit viral-like symptoms. Mol Plant Pathol 2:27-36

Gowda S, Satyanarayana T, Davis CL, Navas-Castillo J, Albiach-Martí MR, Mawassi M, Valkov N, Bar-Joseph M, Moreno P, Dawson WO (2000) The p20 gene product of Citrus tristeza virus accumulates in the amorphous inclusion bodies. Virology 274:246-254
Harper SJ (2013) Citrus tristeza virus: evolution of complex and varied genotypic groups. Front Microbiol 4:93

Heinlein M (2015) Plant virus replication and movement. Virology 479-480:657-671

Hilf ME, Karasev AV, Pappu HR, Gumpf DJ, Niblett CL, Garnsey SM (1995) Characterization of citrus tristeza virus subgenomic RNAs in infected tissue. Virology 208:576-582

Huang TS, Nagy PD (2011) Direct inhibition of tombusvirus plusstrand RNA synthesis by a dominant negative mutant of a host metabolic enzyme, glyceraldehyde-3-phosphate dehydrogenase, in yeast and plants. J Virol 85:9090-9102

Jenkins JL, Tanner JJ (2006) High-resolution structure of human D-glyceraldehyde-3-phosphate dehydrogenase. Acta Crystallogr D Biol Crystallogr 62:290-301

Kaido M, Abe K, Mine A, Hyodo K, Taniguchi T, Taniguchi H, Mise $\mathrm{K}$, Okuno T (2014) GAPDH-A recruits a plant virus movement protein to cortical virus replication complexes to facilitate viral cell-to-cell movement. PLoS Pathog 10:e1004505

Kang SH, Dao TNM, Kim OK, Folimonova SY (2017) Self-interaction of Citrus tristeza virus $\mathrm{p} 33$ protein via $\mathrm{N}$-terminal helix. Virus Res 233:29-34

Karasev AV, Boyko VP, Gowda S, Nikolaeva O, Hilf ME, Koonin EV, Niblett CL, Cline K, Gumpf DJ, Lee RF, Garnsey SM, Lewandowski DJ, Dawson WO (1995) Complete sequence of the Citrus tristeza virus RNA genome. Virology 208:511-520

Lai MMC, Cavanagh D (1997) The molecular biology of coronaviruses. Adv Virus Res 48:1-100

López C, Navas-Castillo J, Gowda S, Moreno P, Flores R (2000) The $23 \mathrm{kDa}$ protein coded by the 3 '-terminal gene of Citrus tristeza virus is an RNA-binding protein. Virology 269:462-470

Lu R, Folimonov A, Shintaku M, Li WX, Falk BW, Dawson WO, Ding SW (2004) Three distinct suppressors of RNA silencing encoded by a $20-\mathrm{kb}$ viral RNA genome. Proc Natl Acad Sci USA 101:15742-15747

Marsh LE, Huntley CC, Pogue GP, Connell JP, Hall TC (1991) Regulation of $(+):(-)$ strand asymmetry in replication of brome mosaic virus RNA. Virology 182:76-83

Mawassi M, Mietkiewska E, Gofman R, Yang G, Bar-Joseph M (1996) Unusual sequence relationships between two isolates of Citrus tristeza virus. J Gen Virol 77:2359-2364

Moreno P, Ambrós S, Albiach-Martí MR, Guerri J, Peña L (2008) Citrus tristeza virus: a pathogen that changed the course of the citrus industry. Mol Plant Pathol 9:251-268

Nassuth A, Bol JF (1983) Altered balance of the synthesis of plusand minus-strand RNAs induced by RNAs 1 and 2 of alfalfa mosaic virus in the absence of RNA3. Virology 124:75-85

Petrik J, Parker H, Alexander G (1999) Human hepatic glyceraldehyde-3-phosphate dehydrogenase binds to the poly(U) tract of the $3^{\prime}$ non-coding region of hepatitis $\mathrm{C}$ virus genomic RNA. J Gen Virol 80:3109-3113

Pogany J, Nagy PD (2008) Authentic replication and recombination of tomato bushy stunt virus RNA in a cell-free extract from yeast. J Virol 82:5967-5980

Prasanth KR, Huang YW, Liou MR, Wang RY, Hu CC, Tsai CH, Meng M, Lin NS, Hsu YH (2011) Glyceraldehyde 3-phosphate dehydrogenase negatively regulates the replication of bamboo mosaic virus and its associated satellite RNA. J Virol 85:8829-8840

Ruiz-Ruiz S, Moreno P, Guerri J, Ambrós S (2007) A real-time RTPCR assay for detection and absolute quantitation of citrus tristeza virus in different plant tissues. J Virol Methods 145:96-105

Ruiz-Ruiz S, Soler N, Sánchez-Navarro J, Fagoaga C, López C, Navarro L, Moreno P, Peña L, Flores R (2013) Citrus tristeza virus p23: determinants for nucleolar localization and their influence on suppression of RNA silencing and pathogenesis. Mol Plant Microb Interact 26:306-318 
Sambade A, López C, Rubio L, Flores R, Guerri J, Moreno P (2003) Polymorphism of a specific region in gene p23 of Citrus tristeza virus allows discrimination between mild and severe isolates. Arch Virol 148:2325-2340

Satyanarayana T, Gowda S, Boyko VP, Albiach-Martí MR, Mawassi M, Navas-Castillo J, Karasev AV, Dolja V, Hilf ME, Lewandowski DJ, Moreno P, Bar-Joseph M, Garnsey SM, Dawson WO (1999) An engineered closterovirus RNA replicon and analysis of heterologous terminal sequences for replication. Proc Natl Acad Sci USA 96:7433-7438

Satyanarayana T, Gowda S, Ayllón MA, Albiach-Martí MR, Rabindram R, Dawson WO (2002) The p23 protein of Citrus tristeza virus controls asymmetrical RNA accumulation. J Virol 76:473-483

Soler N, Fagoaga C, López C, Moreno P, Navarro L, Flores R, Peña L (2014) Symptoms induced by transgenic expression of $\mathrm{p} 23$ from Citrus tristeza virus in phloem-associated cells of Mexican lime mimic virus infection without the aberrations accompanying constitutive expression. Mol Plant Pathol 16:388-399

Vives MC, Rubio L, López C, Navas-Castillo J, Albiach-Martí MR, Dawson WO, Guerri J, Flores R, Moreno P (1999) The complete genome sequence of the major component of a mild Citrus tristeza virus isolate. J Gen Virol 80:811-816
Vojtek AB, Hollenberg SM (1995) Ras-Raf interaction: two-hybrid analysis. Methods Enzymol 255:331-342

Wang RY, Nagy PD (2008) Tomato bushy stunt virus coopts the RNAbinding function of a host metabolic enzyme for viral genomic RNA synthesis. Cell Host Microb 3:178-187

White MR, Garcin ED (2016) The sweet side of RNA regulation: glyceraldehyde-3-phosphate dehydrogenase as a noncanonical RNA-binding protein. Wiley Interdisc Rev RNA 7:53-70

Yang ZN, Mathews DH, Dodds JA, Mirkov TE (1999) Molecular characterization of an isolate of Citrus tristeza virus that causes severe symptoms in sweet orange. Virus Genes 19:131-142

Yang SH, Liu M, Tien CF, Chou SJ, Chang RY (2009) Glyceraldehyde3-phosphate dehydrogenase (GAPDH) interaction with 3' ends of Japanese encephalitis virus RNA and colocalization with the viral NS5 protein. J Biomed Sci 16:1-10

Yi M, Schultz DE, Lemon SM (2000) Functional significance of the interaction of hepatitis A virus RNA with glyceraldehyde 3-phosphate dehydrogenase (GAPDH): opposing effects of GAPDH and polypyrimidine tract binding protein on internal ribosome entry site function. J Virol 74:6459-6468 